\title{
Exploring the predation of UK bumblebees (Apidae, Bombus spp.) by the invasive pitcher plant Sarracenia purpurea: examining the effects of annual variation, seasonal variation, plant density and bumblebee gender
}

\author{
Elizabeth Franklin ${ }^{1} \cdot$ Damian Evans $^{2} \cdot$ Ann Thornton ${ }^{1}$.

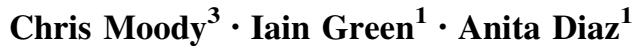

Received: 31 July 2015/Accepted: 14 October 2016/Published online: 26 November 2016

(c) The Author(s) 2016. This article is published with open access at Springerlink.com

\begin{abstract}
Invasive carnivorous plant species can impact the native invertebrate communities on which they prey. This article explores the predation of native UK bumblebees (Bombus spp.) by the invasive pitcher plant species Sarracenia purpurea and discusses the potential effect of $S$. purpurea on native bumblebees. Specifically, it evaluates whether the extent to which bumblebees are captured varies (i) over successive years, (ii) across June and July, (iii) with density of distribution of pitchers or (iv) with bumblebee gender. Pitcher contents were examined from an established population of Sarracenia purpurea growing in Dorset, UK. Results show that the total extent to which bumblebees were captured differed over the years 2012-2014 inclusive. A 1-year study in 2013 showed that more bumblebees were caught in July than in June and more bumblebees were captured when pitchers grew at high density. Results from 2013 also showed that more pitchers caught more than one bumblebee than would be expected based on a normal probability distribution and that this phenomenon affects female and male bumblebees equally. We discuss possible reasons for these results
\end{abstract}

Handling Editor: Katja Hogendoorn.

Elizabeth Franklin

efranklin@bournemouth.ac.uk

1 Department of Life and Environmental Sciences, Faculty of Science and Technology, Bournemouth University, Talbot Campus, Poole, Dorset, UK

2 Department of Archaeology, Anthropology and Forensic Science, Faculty of Science and Technology, Bournemouth University, Talbot Campus, Poole, Dorset, UK

3 Department of Animal and Plant Sciences, University of Sheffield, Alfred Denny Building, Western Bank, Sheffield, UK including that the bumblebees may be using $S$. purpurea as a resource. Further work is required to establish the exact underpinning mechanisms and the relative roles of plant and bumblebee behaviour within the relationship. Such interaction complexity may have consequences for consideration in invasive carnivorous plant management.

Keywords Pitcher plants - Bumblebees - Invasive · Pollinators

\section{Introduction}

Invasive species can potentially impact upon native habitats by affecting both the abundance and population dynamics of native species (Vilá and Weiner 2004; Vilà et al. 2011). Invasive plant species often out compete native plants (Vilá and Weiner 2004), change native plant community composition and impact the invertebrate consumers and decomposers of those affected species (Levine et al. 2003). When the invasive plant is a carnivorous one, it can also potentially act as a new predator in the ecosystem. Carnivorous plants engage in the luring, trapping and digestion of prey items, consisting of predominantly invertebrates (Darwin 1875; Mithöfer 2010). They often live in low nutrient habitats, requiring them to supplement their nutrient requirement from invertebrate prey (Adamec 1997). Pitcher plants, of the genus Sarracenia, employ liquid-filled traps with lures into which invertebrates fall and cannot escape (Bennett and Ellison 2009; Mithöfer 2010). These consume many types of invertebrate prey, primarily, flies, beetles and ants (Cresswell 1991; Owen and Taylor 1994), but grasshoppers, bees, wasps, spiders, moths, leafhoppers and springtails have also been reported (Newell and Nastase 1998; Bhattarai and Horner 
2009). The extra-floral nectaries (on the lip roll in Sarracenia purpurea) (Deppe et al. 2000; Bennett and Ellison 2009) and leaf colouration (Schaefer and Ruxton 2008) of pitchers may be particularly attractive to nectivorous pollinators such as bees, bumblebees and hoverflies. With many of these wild pollinator species already in decline (Plowright and Laverty 1987; Corbet et al. 1991; Kearns et al. 1998; Steffan-Dewenter et al. 2005; Potts et al. 2010), and pollinators being important ecosystem service providers (Losey and Vaughan 2006), carnivorous plants could have an impact on the wider landscape through the removal of pollinators.

Plants from the Sarraceniaceae are not native to the British Isles (Walker 2014). Nevertheless, several introduced populations of the Northern pitcher plant (Sarracenia purpurea) have become established in Europe including in Switzerland, Germany, France, Czech Republic, Ireland and England (Foss and O'Connell 1985; Parisod et al. 2005; Gebühr et al. 2006; IPCC 2009; BBC News 2012; Pyšek et al. 2012; Sanderson 2012; Long 2013; Walker 2014). Sarracenia purpurea is native to North American wetlands, and the climate in the British Isles is within its adaptive range (Walker 2014). Sarracenia purpurea has been established in Irish peat lands since at least 1906 (Foss and O'Connell 1985), populations were reported in 10 peat land sites around Ireland in 2009 and are considered as a concern to wetland conservation (IPCC 2009). Sarracenia purpurea has also been classified as having a moderate impact and moderate risk to native habitats in a report by the GB non-native species risk analysis (Walker 2015). At sites in the Lake District, Cumbria and the New forest Dorset, UK, Sarracenia pitcher plants have been removed, to eliminate any possible threat they had on native wetland flora and fauna (BBC News 2012; Sanderson 2012; Long 2013; Walker 2014). To the knowledge of the authors, this decision was not based on published studies on the capture of invertebrates in pitcher plants in the British Isles and there are no publications indicating that pitcher plants deplete local invertebrate populations. However, several accounts of pitcher capture contents from the UK and continental Europe list: mites, caddis flies, midges, beetles, parasitic wasps, spiders and dragonflies among the prey items (Owen and Taylor 1994; IPCC 2009; Adlassnig et al. 2010; BBC News 2012; Long 2013; Walker 2014).

This article considers the capture instances of bumblebees (Bombus spp.) in pitcher plants (Sarracenia purpurea) on Lower Hyde Heath, Dorset, UK. It is not surprising that pitcher plants would prey on bumblebees, as bumblebees may be attracted to the nectar produced by pitchers (Cresswell 1991; Deppe et al. 2000; Bennett and Ellison 2009), the leaf colouration (Schaefer and Ruxton 2008), UV reflection (Joel et al. 1985), attractive volatiles
(Jürgens et al. 2009) and possibly stored water (Ferry and Corbet 1996). Bumblebees from the genus Bombus are also known pollinators of pitcher plants in their native habitat and therefore also might be attracted to the flowers of $S$. purpurea in the UK (Schnell 1983; Ne'eman et al. 2006; Horner 2014). These pollen and nectar resources could be attracting bumblebees into wet areas which otherwise would have limited floral resource availability compared with the surrounding dry heathland (Rodwell 1991; Ballantyne et al. 2015). Bumblebees are of interest because, first, to the authors' knowledge bumblebees have not been reported as pitcher plant prey and they have not been observed pollinating wild pitcher plants in the UK, second, they are of conservation interest due to recent declines in their numbers (Goulson 2003) and, third, their importance as ecosystem service providers (Potts et al. 2010). Therefore, this article explores the predation of UK bumblebees by $S$. purpurea and discusses the potential effect of these plants on native bumblebees in relation to other invertebrates captured. Specifically it evaluates whether the extent to which bumblebees are captured varies: (i) over successive years: if pitchers consume bumblebees in large quantities over successive years, they could have a significant impact on local populations; (ii) across June and July: at certain times of season bumblebee colonies could be impacted more substantially by the loss of colony members or it could affect future colony reproduction; (iii) with density of distribution of pitchers: if bumblebees are using pitchers as a resource, dense patches could recruit more bumblebees both as a prey and as pollinators; (iv) with bumblebee gender: investigating whether pitcher plants are attracting a similar proportion of male bees to females and assess the effect this could have on colony reproduction, as only males and queens reproduce.

\section{Materials and methods}

\section{Study site}

The study site is an area of lowland wet heath in Lower Hyde Heath near Wareham, Dorset, UK. The precise location has been withheld as it is a site of significant scientific interest (SSSI) and its protection has been requested by the land owners. The site has an isolated population of the invasive pitcher plant Sarracenia purpurea that is found over an area of $1 \mathrm{~km}^{2}$ and has been established for at least 10 years (Mark Warn Personal Communication). The Sarracenia purpurea grows in a national vegetation classification (NVC) M2 categorised mire habitat (Rodwell 1991), and the scale of the site and distribution of pitchers is depicted in Fig. 1. Sarracenia purpurea grows in dense patches of different sizes from 
Fig. 1 Distribution and scale of the Lower Hyde Heath Sarracenia purpurea population. As $S$. purpurea grows in dense patches, patches of $100 \%$ pitcher cover were plotted by estimated patch size: closed circles $1 \mathrm{~m}^{2}$, crosses $0.5 \mathrm{~m}^{2}$ and open triangles $0.25 \mathrm{~m}^{2}$. Areas containing small or individual plants of $<10$ pitchers were mapped as a shaded area. The entire patch is approximately $1 \mathrm{~km}^{2}$

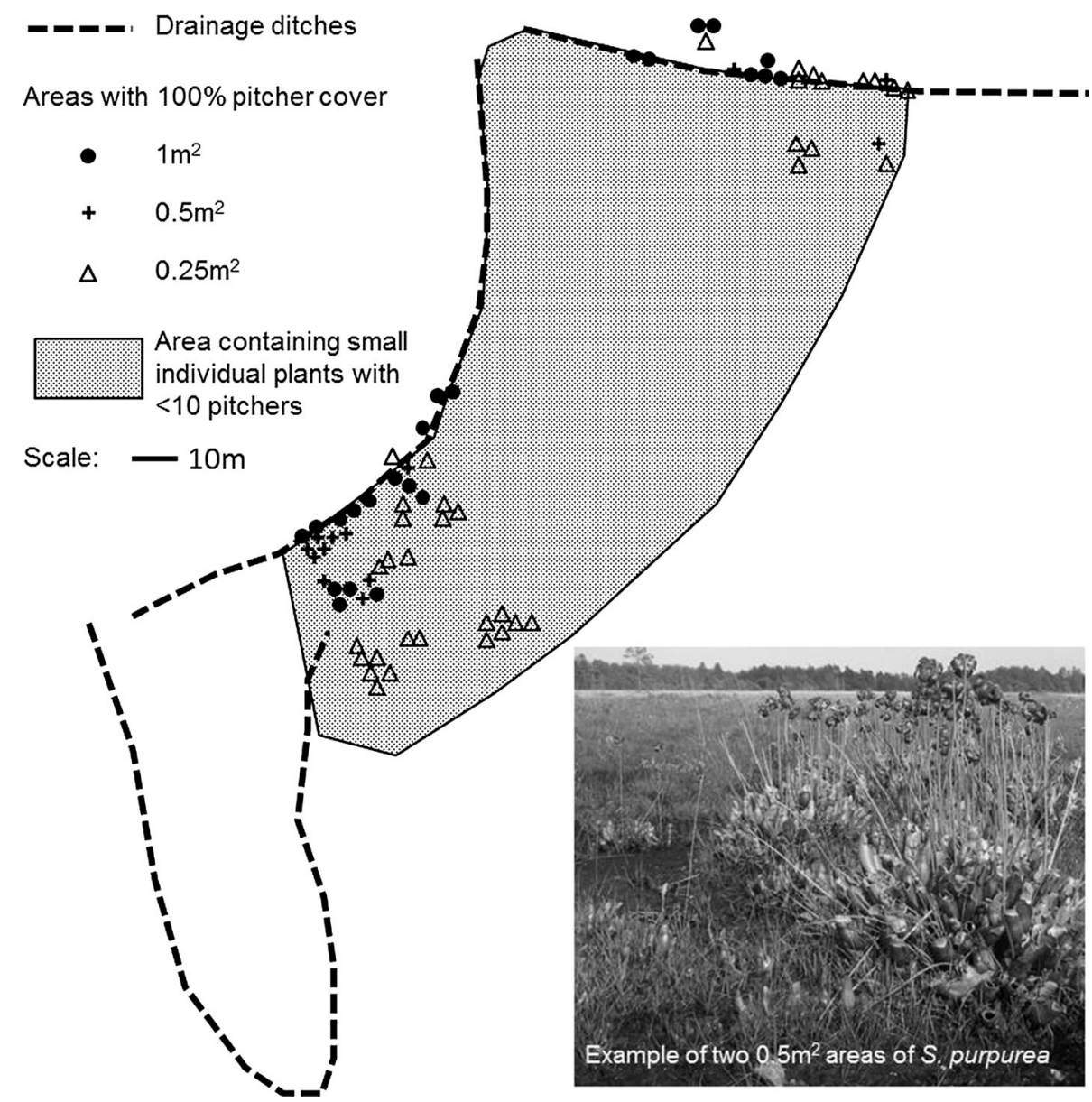

individual plants to large patches of multiple plants which are undefinable from each other (Fig. 1). Therefore, patches of $100 \%$ pitcher cover of sizes $0.25,0.5$ and $1 \mathrm{~m}^{2}$ were mapped and the area indicated where small patches or individual plants ( $<10$ pitchers) were growing (Fig. 1).

\section{Pitcher sampling and collection}

The entire contents of pitchers were collected over three successive years: 2012 (40 pitchers), 2013 (25 pitchers) and 2014 (25 pitchers) to explore the constancy of pitcher captures over successive years. Pitchers were picked from across the whole population with the following restrictions: only pitchers in peak capture condition (not newly opened or damaged) were selected; to avoid possibility of bias, all pitchers were selected from a sufficient distance to prevent contents being visible by the researcher and to avoid pseudo-replication all pitchers selected were spaced by at least $3 \mathrm{~m}$. Pitchers were picked by snipping them off with scissors low down near the base of the plant so that the pitcher stayed intact and contents did not drain through or spill out. The effect of season, pitcher density and bumblebee gender were explored during an intensive study in 2013. This study examined pitcher contents in June and July to explore the captures of bumblebees in two of their peak months of activity (Prŷs-Jones and Corbet 2011). In the middle of each month, 25 pitchers were selected from across the whole population as described above.

To assess the effect of plant density, the percentage cover of pitcher plants was classified within a $0.5 \mathrm{~m}$ radius of each of selected pitcher as either a dense patch (percentage cover of pitcher plants of $>70 \%$ ) or a sparse patch (percentage cover of pitcher plants of $<20 \%$ ). Again samples were collected with the following restrictions: only pitchers in peak capture condition (not newly opened or damaged) were selected; to avoid possibility of bias, all pitchers were selected from a sufficient distance in dense or sparse patches to prevent contents being visible by the researcher and to avoid pseudo-replication all pitchers selected were spaced by at least $3 \mathrm{~m}$. The number of samples collected varied due to some pitcher contents being unidentifiable when explored in the laboratory; June sparse $n=46$, June dense $n=27$, July sparse $n=46$, July dense $n=33$. 


\section{Pitcher content analysis}

Pitcher contents were examined in the laboratory by dissecting the pitcher leaf and preserving the solid contents in $70 \%$ industrial methylated spirit. The number of invertebrate individuals from the groups (Diptera, Coleoptera, Hymenoptera, Araneae and Isopoda), the number of ants and wasps and the number of Bombus spp. individuals were counted to explore the captures over successive years. To explore the effect of month and pitcher density, the number of captured Bombus spp. individuals was counted and the species and gender of bumblebee individuals was identified. Bombus terrestris and Bombus lucorum were distinguished by the presence or absence of buff colouration between the black and white at the distal end of the abdomen (Prŷs-Jones and Corbet 2011). Queens and workers were not differentiated.

\section{Data analysis}

A Kruskal-Wallis analysis was used to compare the abundances of invertebrates, Hymenoptera, ants and wasps and bumblebees in pitchers as the large number of empty pitchers resulted in a nonparametric data set. Likewise, a Mann-Whitney analysis was used to compare bumblebee numbers over months and the effect of pitcher density on bumblebee captures due to the nonparametric data set. A Kolmogorov-Smirnov test was used to explore the distribution of the frequencies of bumblebee captures. The Kruskal-Wallis, Mann-Whitney U, Kolmogorov-Smirnov tests were conducted in IBM SPSS Statistics version 21. A Chi-squared test was used to compare the frequencies of bumblebee captures to those expected, and a $G$ test was used to investigate whether the company bumblebees had on capturing was related to gender. The Chi-square test and $G$ test were completed in Microsoft Excel 2010.

\section{Results}

\section{Variation in pitcher captures over successive years}

The total number of invertebrate individuals including all groups significantly varied from year to year (KruskalWallis $H_{(2,89)}=13.955, P=0.001$, Fig. 2a). Hymenoptera individuals captured also appeared to vary significantly over successive years (Kruskal-Wallis $H_{(2,89)}=10.452$, $P=0.005$, Fig. 2b). Within the Hymenoptera, it appears to be the variation in bumblebee counts that affect the overall Hymenopteran numbers, as bumblebee captures significantly vary over successive years where numbers of wasps and ants do not appear to vary significantly over years (ants and wasps, Kruskal-Wallis $H_{(2,89)}=2.561, P=0.278$, Fig. 2c and bumblebees, Kruskal-Wallis $H_{(2,89)}=16.137$,
$P<0.001$, Fig. 2d). The year that most bumblebees were captured in pitchers was 2013.

\section{Variation between June and July in the number of captured bumblebees}

There were significantly more bumblebees present in pitchers in July $(n=25, \bar{x}=1.12, \sigma=1.76)$ than in June $2013(n=25, \quad \bar{x}=0.64, \quad \sigma=1.35), \quad$ [Mann-Whitney $U \quad T_{(1,49)}=223.5$, Wilcoxon $W=548.5, \quad \mathrm{z}=-2.186$, $P=0.029]$.

\section{Effect of plant density on the number of captured bumblebees}

Pitchers in dense groups caught a significantly greater number of bumblebees than pitchers in sparse groups in July (Mann-Whitney $U=462, n_{1}, n_{2}=79, P=0.001$, two tailed, Fig. 3). However, there was no significant difference in the number of bumblebees caught at different densities in June (Mann-Whitney $U T_{(1,72)}=568, n_{1}$, $n_{2}=73, P=0.311$, two tailed, Fig. 3).

\section{Species and gender of captured bumblebees}

A total of 101 bumblebees from six different Bombus spp. (Bombus terrestris, B. lucorum, B. pascuorum, B. pratorum, $B$. hortorum and $B$. lapidaries) were caught in the sample of 170 pitchers. The distribution of bumblebees among pitchers was neither random (Table 1) or normally distributed (one-sample Kolmogorov-Smirnov $D=5.227$, $P<0.001)$. Instead, the pattern showed fewer incidents of single bumblebees in pitchers than expected with a Poisson distribution and more instances of $>3$ bees than expected $\left(\chi_{(170)}^{2}=44.91, P<0.001\right)$. Of the 101 bumblebees captures, 76 individuals were female and 25 were male. Of the female bumblebees, 21 individuals appeared in pitchers alone and 55 with other bumblebees (male or female). Of the 25 male bumblebees, 2 were in pitchers alone, 6 were with other males and 17 with females. The gender of captured bumblebees in pitchers is random ( $G$ test $G=0.5159, D F=2, P=0.773$, Table 2), assuming a 0.752 chance of a female getting caught and a 0.248 of a male getting caught (76/101 and 25/101 respectively).

\section{Discussion}

\section{Variation in pitcher captures over successive years}

Sarracenia purpurea pitchers were found to be capturing a great diversity of invertebrates from the groups Diptera, 
Fig. 2 Captures of invertebrate, Hymenopteran, ant and wasp and Bombus spp. individuals over successive years 2012-14. The number of individuals caught per pitcher in 2012 $n=40,2013 n=25,2014$ $n=25$. a Invertebrates from all groups $(5$ outliers $>40$ individuals have been removed for visual clarity),

b Hymenopteran individuals (1 outlier $>20$ individuals has been removed), $\mathbf{c}$ ants and wasps (6 outliers $>10$ individuals have been removed), d Bombus spp. (no outliers have been removed Central bars indicate the median, boxes encompass the interquartile ranges and the whiskers 1.5 times the interquartile range
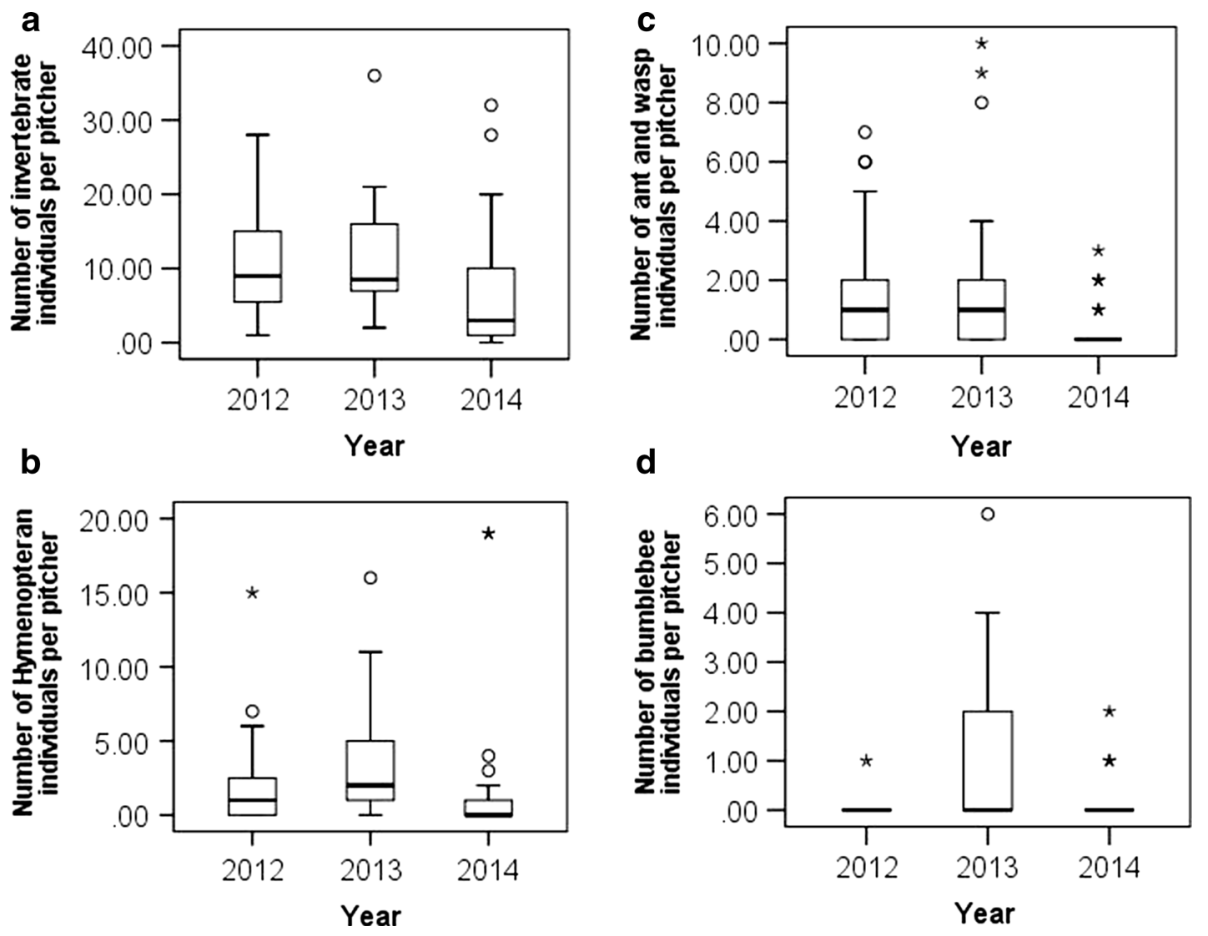

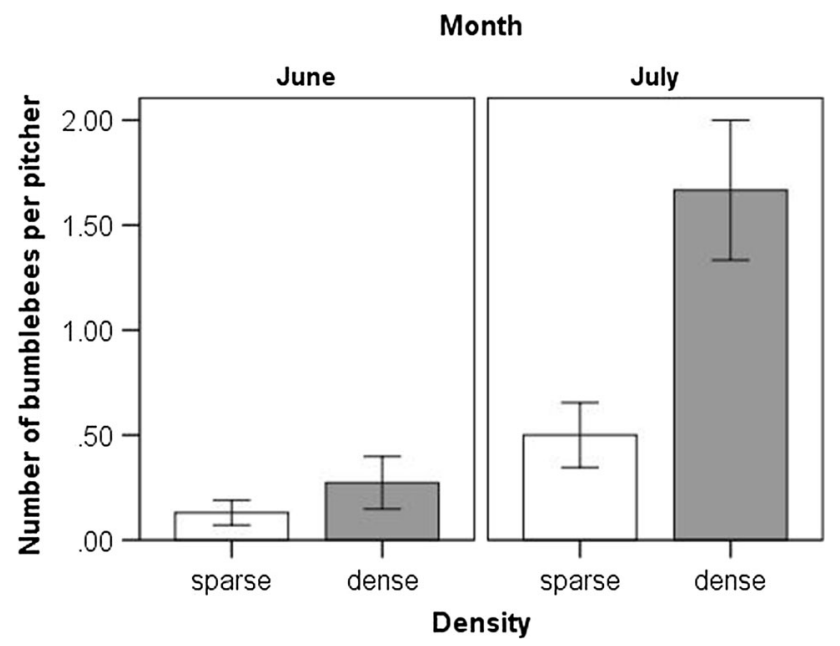

Fig. 3 Comparison of the number of Bombus spp. individuals caught in pitchers in either densely ( $>70 \%$ cover) or sparsely $(<20 \%$ cover) distributed areas of pitcher plants in June and July 2013. June sparse $n=46$, June dense $n=27$, July sparse $n=46$, July dense $n=33$. Bars indicate the mean number of bumblebees and the whiskers $\pm 1 \mathrm{SE}$

Coleoptera, Hymenoptera, Araneae, Isopoda and Bombus spp. The captures of invertebrates within Sarracenia purpurea pitchers vary over successive years, both the overall numbers of invertebrates and the number of Bombus spp. varying significantly. The inconsistency of bumblebee captures over the years of this study could be a result of the effect of single or combined factors such as weather (Moret and Schmid-Hemplel 2000), a change in the abundance of bumblebees (Williams et al. 2001) and/or the condition of the pitcher plants (Wolfe 1981; Newell and Nastase 1998; Bauer et al. 2015). The Lower Hyde Heath site is surrounded by dry heath with abundant heather and gorse (Erica tetralix, Erica cinerea, Calluna vulgaris, Ulex minor and Ulex europaeus), high-quality habitat for pollinators (Ballantyne et al. 2015). Bumblebees were abundant in the surrounding heathland (within $3 \mathrm{~km}$ of the site, $50^{\circ} 43^{\prime} \mathrm{N} 2^{\circ} 07^{\prime} \mathrm{W}$ ) during the duration of the study (JuneAugust 2013 and May 2014) with $67 \%$ of observations coming from Bombus spp. (Ballantyne et al. 2015). The same site was sampled previously in 2001-2004 and also showed the presence of Bombus spp. (Forup et al. 2008). However, the wet bog itself possesses limited resources to attract bees other than the pitcher plants. The areas where the pitchers are growing are NVC classified M2, so the only flowers in and around the pitchers are occasional bog asphodel (Narthecium ossifragum), oblong-leaved sundew (Drosera intermedia) and round-leaved sundew (Drosera rotundifolia) (Rodwell 1991). There will also be the occasional cross-leaved heather (Erica tetralix) in the surrounding area outside the M2 classified area.

Local monthly weather data suggest that 2013 and 2014 were quite similar for June and July in terms of temperature, sunshine and rainfall (MetOffice 2014). However, the weather data summarise months and as such does not have the resolution to look for extended periods of dry and wet weather. Extremes in weather possibly impacted bumblebee foraging behaviour, with hot dry weather maybe inducing water foraging from within pitchers (Ferry and Corbet 1996) and wet weather inhibiting foraging 
Table 1 Distribution of bumblebees in pitchers

\begin{tabular}{lccc}
\hline Number of individuals per pitcher & Number of observations & Expected observations & Chi-square contributions \\
\hline 0 & 121 & 93.85 & 7.86 \\
1 & 23 & 55.76 & 19.24 \\
2 & 14 & 16.56 & 0.40 \\
$\geq 3$ & 12 & 3.83 & 17.42 \\
Chi-square value $=44.91$ & & $P<0.001$ &
\end{tabular}

Analysis of the distribution of bumblebees within pitchers detailing the types of observations, numbers of observations, expected values and Chisquare contributions. From this, bumblebees appeared on their own less frequently than expected and appeared in groups of 3 or more, more than expected

Table 2 Distribution of the gender of pairs of captured bumblebees in pitchers

\begin{tabular}{llcc}
\hline & & Expected & Observed events \\
\hline$P(\circ$ and + ) & 0.566219 & 14.721694 & 16 \\
$P(\uparrow$ and $\hat{\circ})$ & 0.372512 & 9.68532497 & 8 \\
$P(\widehat{\circ}$ and $\widehat{\jmath})$ & 0.061269 & 1.59298108 & 2 \\
\hline
\end{tabular}

Assuming the simplest combination of two bumblebees per sample with the probability of getting a female 0.7524 and a male 0.2475 (76/ 101 and 25/101, respectively) the expected and observed number of pairing events

altogether (Moret and Schmid-Hemplel 2000). In addition, dry weather may reduce the efficiency of pitcher plant trapping due to the absence of trapping liqueur or reducing surface slipperiness (Newell and Nastase 1998; Bauer et al. 2015).

\section{Variation between June and July in the number of captured bumblebees}

The finding that there were a greater number of bumblebee captures in July than in June in 2013 is likely to be linked to the abundance of bumblebees, as colonies of the bumblebee species captured reach their maximum sizes and demand for resources in July and August (Prys-Jones 1982). This is also the time at which these bumblebee species produce their sexually reproductive individuals, queens and male bees (Prys-Jones 1982). It is also likely that there would have been a greater number of male bumblebees around in the July period and in addition these males would have been outside the nest, searching for queens (Prys-Jones 1982). The flowers of Sarracenia purpurea, which bloom in June and July in the UK, could also be attracting bumblebees. Bumblebees are known pollinators of pitcher plants in their native habitats (Schnell 1983; Ne'eman et al. 2006; Horner 2014) and in the UK, are pollinators of commercially grown plants (South West Carnivorous Plants personal communication). The bumblebee Bombus affinis has been recorded to take large pollen loads from $S$. purpurea in its native habitat (Ne'eman et al. 2006). If the same pollination occurs in the UK, $S$. purpurea may be beneficial to bumblebees providing them with additional pollen resources that would otherwise not be present in wet bog areas.

Bumblebee colonies store very few resources, making them sensitive to changes in resource availability; therefore, bumblebee colonies are at their most vulnerable when they are founding in spring and when their colonies are at maximum size during the production of sexual brood (Williams and Christianson 1991; Westphal et al. 2009). Although this study did not explore the effects of $S$. purpurea on bumblebees early in the season, it is unlikely that $S$. purpurea will negatively impact bumblebees during founding. This is because $S$. purpurea plants flower and produce new pitchers in June and July (Walker 2014) and pitchers are generally far less viable in their second year (Wolfe 1981; Rice 2012). At Lower Hyde Heath, this reduction in viability in the second year is particularly pronounced as the pitchers are being winter grazed by wild Sika deer (Anita Diaz Personal Observation).

There is a potential for Sarracenia purpurea to suffer from pollinator-prey conflict as bumblebees are both potential pollinators and prey (Jürgens et al. 2012). For a conflict to occur, plant fitness must depend on pollinators and pollinators must also be possible prey. However, Sarracenia purpurea seed set is reduced more by starvation from prey $(14 \%)$ than by not being pollinated $(<10 \%)$ (Ne'eman et al. 2006) so it is unlikely to suffer from this conflict. In addition, many pitcher plants use temporal separation between flowering and pitcher production to avoid predating upon their pollinators (Anderson and Midley 2001). Sarracenia purpurea in the UK overlap their pitcher and flower production.

\section{Effect of plant density on the number of captured bumblebees}

Previous studies have shown that Sarracenia invertebrate captures do not change or decrease with increased plant 
density (Cresswell 1991). However, this study observed that more bumblebees are captured by pitcher plants in dense patches. This may be driven by bumblebees foraging for nectar or pollen and using optimal foraging strategies, as insects preferentially visit bigger floral patches (Thomson 1981; Schmid-Hempel and Speiser 1988; Grindeland et al. 2005; Weber and Kolb 2013).

The trapping efficiency of pitcher plants could also have an effect on bumblebees foraging interactions, whether that is the general efficiency of the pitchers (Newell and Nastase 1998) or an intermittency in their effectiveness (Bauer et al. 2015). In a study by Newell and Nastase (1998) the capture efficiency of $S$. purpurea was found to be 0.83 and $0.93 \%$ efficient in the two successive trials. This means approximately only 1 in 100 invertebrates that visit the pitchers were actually caught. From their experiment, Newell and Nastase (1998) estimate that pitcher with five separate pitcher traps would be likely to catch one prey item every three days (Newell and Nastase 1998). Newell and Nastase (1998) also found that ants, although the most abundant prey item in pitchers, were also the one with the lowest capture rate, at $0.37 \%$. This low capture rate appeared due to the ants' stable footing and ability to escape (Newell and Nastase 1998). In a similar scenario, pitcher plants could be providing bumblebees with a substantial nectar resource (Deppe et al. 2000) with the majority of interactions with pitcher plants being positive rather than negative. Bumblebees are strong fliers and can lift on average $53 \%$ of their own body weight (Buchwald and Dudley 2010) so it is possible that bumblebees could have a high escape rate from pitchers. For confirmation of this, observations of live bumblebee and pitcher plant trap interactions need to be obtained. It has been reported in some pitcher plants that there is an intermittent nature to their trapping (Bauer et al. 2015). In the Nepenthes spp. pitcher plants, capture rate is greatly affected by how slippery the surface of the trap is and that is dependent on moisture (Bauer et al. 2015). In the natural environment, this results in the intermittent effectiveness of traps. During dry, inactive periods, it is probable that invertebrates can feed at the pitchers with a much lower risk of becoming trapped. In the case of the ants in the study, creating recruitment trails to the inactive, dry pitcher plants. This is adaptive for the plant as when its traps become active, it traps returning and recruited insects (Bauer et al. 2015). Whether Sarracenia purpurea captures more effectively with a wet surface was not tested in this study, but the presence of water within the traps is known to be important for prey capture and retention (Newell and Nastase 1998). S. purpurea pitchers can become dry, as the pitcher fluid comprises mainly of captured rain water (Adlassnig et al. 2010). During dry periods, it is plausible that bumblebees and other insects could be feeding from the plants at a much lower risk level.

\section{Species and gender of captured bumblebees}

It is of interest that male bumblebees are being attracted to and trapped in pitcher plants despite only being driven to forage for themselves (Goulson 2003) and they would mainly be attracted by the nectar not the pollen from flowers. The distribution of bumblebees in pitchers did not indicate an effect of gender on capture. There was no indication that the opposite or same sex attracted others into the traps.

Males are reproductive units for colonies unlike the workers (Wilson 1971), although workers do contribute indirectly to the colony fitness through foraging and late season male production (Free et al. 1969). Laboratoryreared colonies of Bombus terrestris have been known to have an average of 111.78 males per colony, although colonies vary greatly in male or queen production (Duchateau et al. 2004). This study caught 25 males in a sample of the Lower Hyde Heath pitcher population. It is not possible to estimate the impact of the entire population of pitchers in terms of bumblebee consumption as it is almost impossible to quantify the numbers of pitchers. However, the patch is restricted to an area of about $1 \mathrm{~km}^{2}$ and due to the low seed dispersal they are likely to remain isolated (Ellison and Parker 2002; Walker 2015). It is unknown how many colonies the sampled bumblebees come from, as many of our captured bumblebees could be sisters from the same colony and there are no accounts of the density of bumblebee nests in wet heathland areas. The results show there were two representative species for males and six for females. In order to ascertain the number of colonies, the plants would have been affecting and sistership would need to be evaluated using microsatellite markers (Knight et al. 2005).

The observation of high instances of multiple bumblebees in pitchers and low numbers of single captures seems at first counterintuitive, for if a bumblebee observes another visiting an inflorescence, then that resource is likely to be depleted, and therefore not worth visiting immediately (Goulson 2003). However, pitcher plants do not fit a standard flower format and this may result in bumblebees following others to pitcher plants due to the novelty of the resource; it has been suggested that social information from conspecifics and intraspecifics could be adaptive when it alluded to a novel resource (Worden and Papaj 2005; Kawaguchi et al. 2007; Avarguès-Weber and Chittka 2014). Bumblebees have also been shown to follow one another's choices in dangerous situations (Dawson and Chittka 2014). This interpretation of bumblebee distribution is speculative in terms of foraging on pitcher plants 
because we do not know the proximity of events in time, only that the distribution of bumblebees is not normal or random. There is also a possibility that the plant changes in response to capturing prey, maybe on 'knowing' there are prey available changes lure production, volatiles or nectar (Jürgens et al. 2009). Current interpretations are based on data about dead bumblebees. Observations of live interactions with pitcher plants are needed to affirm the above speculations.

\section{The effect of Sarracenia purpurea on native bumblebees}

It is almost impossible to quantify the effect that the Sarracenia purpurea population has on the native bumblebees at Lower Hyde Heath as we would need to know how many colonies were present and how their reproduction was affected. However, this study does show that bumblebees are being consumed by the pitcher plants and this is not consistent over years or over the months of June and July (Figs. 1, 2). In this study, none of the bumblebee species caught were considered threatened or rare by the Bumblebee Conservation Trust (2014). This study also produced evidence that the bumblebees could be using the pitcher plants as a resource as bumblebees appear more attracted to dense patches of $S$. purpurea (Fig. 2). Bumblebees are known pollinators of Sarracenia plants in their native habitat (Schnell 1983; Ne'eman et al. 2006; Horner 2014) and as the pitcher plants are growing in M2 mire, the only additional floral resources are occasional bog asphodel (Narthecium ossifragum), oblong-leaved sundew (Drosera intermedia) and round-leaved sundew (Drosera rotundifolia) (Rodwell 1991). These native flowering plants would not recruit a large number of foraging bumblebees compared with the resource rich heathland outside of the mire (Ballantyne et al. 2015). The capture success per invertebrate interaction of Sarracenia purpurea has been reported as about 1 in 100 (Newell and Nastase 1998). This means that the majority of bumblebee interactions with pitcher plants could be beneficial to the bumblebees. There is also the possibility that bumblebees are pollinating the Sarracenia plants allowing them to improve their seed set (Ne'eman et al. 2006). It is unlikely that a population of Sarracenia would have an effect range of beyond $3 \mathrm{~km}$ as this is approximately the maximum foraging range of the furthest foraging bumblebee species found in this study and most species normally forage at much shorter distances (Chapman et al. 2003; Knight et al. 2005). Considering the isolated nature, slow dispersal (Ellison and Parker 2002; Walker 2015) and rarity of such populations (21 were known of in the British Isles in 2014) (Walker 2014), even in a high consumption year the effect of $S$. purpurea on bumblebee populations would be very localised.

\section{Conclusions}

To conclude, the invasive pitcher plant Sarracenia purpurea preys upon native Bombus spp. individuals, both workers and sexually reproducing males. However, sites of this invasive plant are currently rare in the UK and also have been evaluated to be restricted to a local effect due to the plants poor seed dispersal (Ellison and Parker 2002; Walker 2015). Therefore, even in high capture years the effect of these patches would be very localised. It also highlights that interactions between pitcher plants and their prey may not be exclusively exploitive on the part of the pitcher plants and that they provide a food resource for pollinators previously limited in such a habitat. This study also hopes to inspire further research into whether there is an intermittent nature to the trapping by $S$. purpurea, the positive interactions between pollinators and pitcher plants and further investigations into the impact $S$. purpurea has on its naturalised habitat. Research into these interaction complexities has the potential to influence future invasive carnivorous plant management.

Acknowledgments We would like to thank the Forestry Commission and Mr. Mark Warn Forestry Commission Wildlife Ranger for supporting access and permissions to work with the Lower Hyde Heath, Sarracenia purpurea population.

Open Access This article is distributed under the terms of the Creative Commons Attribution 4.0 International License (http://crea tivecommons.org/licenses/by/4.0/), which permits unrestricted use, distribution, and reproduction in any medium, provided you give appropriate credit to the original author(s) and the source, provide a link to the Creative Commons license, and indicate if changes were made.

\section{References}

Adamec L (1997) Mineral nutrition of carnivorous plants: a review. Bot Rev 63:273-299

Adlassnig W, Peroutka M, Lendl T (2010) Traps of carnivorous pitcher plants as a habitat: composition of the fluid, biodiversity and mutualistic activities. Ann Bot. doi:10.1093/aob/mcq238

Anderson B, Midley JJ (2001) Food or sex; pollinator prey conflict in carnivorous plants. Ecol Lett 4:511-513

Avarguès-Weber A, Chittka L (2014) Observational conditioning in flower choice copying by bumblebees (Bombus terrestris): influence of observer distance and demonstrator movement. PLoS ONE. doi:10.1371/journal.pone.0088415

Ballantyne G, Baldock KC, Willmer PG (2015) Constructing more informative plant-pollinator networks: visitation and pollen deposition networks in a heathland plant community. Proc R Soc B 282(1814):20151130

Bauer U, Fedrele W, Seidel H, Grafe UY, Christos IC (2015) How to catch more prey with less effective traps: explaining the evolution of temporarily inactive traps in carnivorous pitcher plants. Proc R Soc B 282:20142675

Bennett KF, Ellison AE (2009) Nectar, not colour, may lure insects to their death. Biol Lett 5:469-472 
Bhattarai GP, Horner JD (2009) The importance of pitcher size in prey capture in the carnivorous plant, Sarracenis alata. Am Midl Nat 161:264-272

Buchwald R, Dudley R (2010) Limits to vertical force and power production in bumblebees (Hymenoptera: Bombus impatiens). J Exp Biol 213:426-432. doi:10.1242/jeb.033563

Bumblebee Conservation Trust (2014) Common bumblebees. Bumblebee Conservation Trust. http://bumblebeeconservation.org/ about-bees/identification/common-bumblebees/. Accessed 1 Apr 2015

Chapman RE, Wang J, Bourke AFG (2003) Genetic analysis of spatial foraging patterns and resource sharing in bumble bee pollinators. Mol Ecol 12:2801-2808

Corbet SA, Williams IH, Osborne JL (1991) Bees and the pollination of crops and wild flowers in the European community. Bee World 72:47-49

Cresswell JE (1991) Capture rates and composition of insect prey of the pitcher plant Sarracenia purpurea. Am Midl Nat 125:1-9

Darwin C (1875) Insectiverous plants. John Murray, London

Dawson EH, Chittka L (2014) Bumblebees (Bombus terrestris) use social information as an indicator of safety in dangerous environments. Proc R Soc Lond B 281:20133174

Deppe JL, Dress WJ, Nastase AJ, Newell SJ, Luciano CS (2000) Diel variation of sugar amount in nectar from pitchers of Sarracenia purpurea $\mathrm{L}$. with and without insect visitors. Am Midl Nat 144:123-132

Duchateau MJ, Velthuis HHW, Boomsma JJ (2004) Sex ratio variation in the bumblebee Bombus terrestris. Behav Ecol 15:71-82. doi:10.1093/beheco/arg087

Ellison AM, Parker JN (2002) Seed dispersal and seedling establishment of Sarracenia purpurea (Sarraceniaceae). Am J Bot 89:1024-1026

Ferry C, Corbet SA (1996) Water collection by bumble bees. J Apic Res 35:120-122

Forup ML, Henson KS, Craze PG, Memmott J (2008) The restoration of ecological interactions: plant-pollinator networks on ancient and restored heathlands. J Appl Ecol 45:742-752

Foss PJ, O'Connell CA (1985) Notes on the ecology of Sarracenia purpurea L. on Irish peatlands. Ir Nat J 21:440-443

Free JB, Weinberg I, Whiten A (1969) The egg-eating behaviour of Bombus lapidaries L. Behaviour 35:313-317

Gebühr C, Pohlon E, Schmidt AR, Küsel K (2006) Development of microalgae communities in phytotelmata of allochtonous populations of Sarracenia purpurea (Sarraceniaceae). Plant Biol $8: 849-860$

Goulson D (2003) Bumblebees: their behavior and ecology. Oxford University Press, Oxford

Grindeland JM, Sletvold N, Ims RA (2005) Effects of floral display size and plant density on polinator visitation rate in a natural population of Digitalis purpurea. Funct Ecol 19:383-390

Horner JD (2014) Phenology and pollinator-prey conflict in the carnivorous plant, Sarracenica alata. Am Midl Nat 171:153-156

IPCC (2009) IPCC'S Peatland Sites Database 2009. http://91.216.241. 2/ ipccie/wp/wp-content/uploads/2012/04/2020ROIsitelist3. pdf. Accessed 11 March 2015

Joel DM, Juniper BE, Dafni A (1985) Ultraviolet patterns in the traps of carnivorous plants. New Phytol 101:585-593

Jürgens A, El-Sayed AM, Suckling DM (2009) Do carnivorous plants use volatiles for attracting prey insects? Funct Ecol 23:875-887

Jürgens A, Sciligo A, Witt T, El-Sayed AM, Suckling DM (2012) Pollinator-prey conflict in carnivorous plants. Biol Rev 87:602-625

Kawaguchi LG, Ohashi K, Toquenaga Y (2007) Contrasting responses of bumblebees to feeding conspecifics on their familiar and unfamiliar flowers. Proc $\mathrm{R}$ Soc Lond B Biol Sci 274:2661-2667
Kearns CA, Inouye DW, Waser NM (1998) Endangered mutualisms: the conservation of plant pollinator interactions. Annu Rev Ecol Syst 29:83-112

Knight ME, Martin AP, Bishop S, Osborne JL, Hale RJ, Sanderson RA, Goulson D (2005) An interspecific comparison of foraging range and nest density of four bumblebee (Bombus) species. Mol Ecol 14:1811-1820

Levine JM, Vilá M, D’Antonio CM, Dukes JS, Grigulis K, Lavorel S (2003) Mechanisms underlying the impact of exotic plant invasions. Proc R Soc Lond B 270:775-781

Long MB (2013) The carnivores in cumbria: the removal and rescue of Sarracenia purpurea friends of Treborth botanic garden Newsletter January 2013. http://www.treborthbotanicgarden.org/ newsletters/NL_Jan_13.pdf. Accessed 15 Mar 2015

Losey JE, Vaughan M (2006) The economic value of ecological services provided by insects. Bioscience 56:311-323

MetOffice (2014) Hurn Data txt. MetOffice. http://www.metoffice. gov.uk/pub/data/weather/uk/climate/stationdata/hurndata.txt. Accessed 1 Apr 2015

Mithöfer A (2010) Carnivorous pitcher plants: insights in an old topic. Phytochemistry 72:1678-1682

Moret Y, Schmid-Hemplel P (2000) Survival for immunity: the price of immune system activation for bumblebee workers. Science 290:1166-1168

Ne'eman G, Ne'eman R, Ellison AM (2006) Limits to reproductive success of Sarracenia purpurea (Sarraceniaceae). Am J Bot 93:1660-1666

Newell SJ, Nastase AJ (1998) Efficiency of insect capture by Sarracenia purpurea (Sarraceniaceae), the Northern Pitcher Plant. Am J Bot 85:88-91

BBC News (2012) Carnivorous plants removed from Lake District. BBC News Archive. http://www.bbc.co.uk/news/uk-englandcumbria-16772704. Accessed 15 Mar 2015

Owen JA, Taylor S (1994) Beetles caught by a pitcher plant naturalised in Highland Scotland. Entomol Rec J Var 106:103-104

Parisod C, Trippi C, Galland N (2005) Genetic variability and founder effect in the Pitcher Plant Sarracenia purpurea (Sarraceniaceae) in populations introduced into Switzerland: from inbreeding to invasion. Ann Bot 95:277-286

Plowright RC, Laverty TM (1987) Bumblebees and crop pollination in Ontario. Proc Entomol Soc Ont 118:155-160

Potts SG, Biesmeijer JC, Kremen C, Neumann P, Schweiger O, Kunin WE (2010) Global pollinator declines: trends, impacts and drivers. Trends Ecol Evol 25:345-353

Prŷs-Jones OE (1982) Ecological studies of foraging and life history in bumblebees. $\mathrm{PhD}$ Thesis, University of Cambridge

Prŷs-Jones OE, Corbet SA (2011) Bumblebees, naturalists' handbooks 6 ecology and identification, 3rd edn. Pelagic publishing, Exeter

Pyšek P, Danihelka J, Sádlo J, Chrtek J Jr, Chytrý M, Jarošík V, Kaplan Z, Krahulec F, Moravcová L, Pergl J, Štajerová K, Tichý L (2012) Catalogue of alien plants of the Czech Republic (2nd edition): checklist update, taxonomic diversity and invasion patterns. Preslia 84:155-255

Rice B (2012) FAQ about Sarracenia purpurea, the purple pitcher plant. International Carnivorous Plant Society. http://www. sarracenia.com/faq/faq5538.html. Accessed 15 Mar 2015

Rodwell JS (1991) British plant communities, vol. 2: mires and heaths. Cambridge University Press, Cambridge

Sanderson N (2012) Ecological importance of Holmsley bog in relation to the exotic pitcher plant Sarracinia purpurea Report

Schaefer MH, Ruxton GD (2008) Fatal attraction: carnivorous plants roll out the red carpet to lure insects. Biol Lett 4:153-155

Schmid- Hempel P, Speiser B (1988) Effects of inflorescence size on pollination in Epilobium angustifolium. Oikos 53:98-104 
Schnell DE (1983) Notes on the pollination of Sarracenia flava L. (Sarraceniaceae) in the Piedmont province of North Carolina. Rhodora 1:405-420

Steffan-Dewenter I, Potts SG, Packer L (2005) Pollinator diversity and crop pollination services are at risk. Trends Ecol Evol 20:651-652

Thomson JD (1981) Temporal components of resource assessment by flower-feeding insects. J Anim Ecol 50:49-59

Vilá M, Weiner J (2004) Are invasive plant species better competitors than native plant species? Evidence from pair-wise experiments. Oikos 105:229-238

Vilà M, Espinar JL, Hejda M, Hulme PE, Jarošík Maron JL, Pergi J, Schaffner U, Sun Y, Pyšek P (2011) Ecological impacts of invasive alien plants: a meta-analysis of their effects on species, communities and ecosystems. Ecol Lett 14:702-708. doi:10. 1111/j.1461-0248.2011.01628.x

Walker KJ (2014) Sarracenia purpurea subsp. purpurea (Sarraceniaceae) naturalised in Britain and Ireland: distribution, ecology, impacts and control. New J Bot 1:33-41

Walker (2015) Risk assessment summary sheet Purple Pitcher plant (Sarracenia purpurea). GB non-native species secretariat. www.
nonnativespecies.org/downloadDocument.cfm?id=1416. Accessed 10 Mar 2016

Weber A, Kolb A (2013) Local plant density, pollination and traitfitness relationships in a perennial herb. Plant Biol 15:335-343

Westphal C, Steffan-Dewenter I, Tscharntke T (2009) Mass flowering oilseed rape improves early colony growth but not sexual reproduction of bumblebees. J Appl Ecol 46:187-193

Williams IH, Christianson DG (1991) Observations on Phacelia tanacetifolia Bentham (Hydrophyllaceae) as a food plant for honey bees and bumble bees. J Apic Res 21:236-245

Williams NM, Minckley RL, Silveira FA (2001) Variation in native bee faunas and its implications for detecting community changes. Conserv Ecol 5:7

Wilson EO (1971) The insect societies. Harvard University Press, Harvard

Wolfe LM (1981) Feeding behavior of a plant: differential prey capture in old and new leaves of the pitcher plant (Sarracenia purpurea). Am Midl Nat 106:352-359

Worden BD, Papaj DR (2005) Flower choice copying in bumblebees. Biol Lett 1:504-507 